\title{
Differential Geometry, Valencia 2001
}


This page is intentionally left blank 


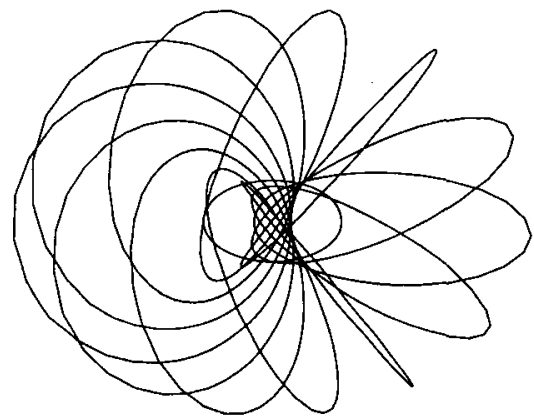

\section{Differential Geometry,}

Valencia 2001

Proceedings of the International Conference held to honour the 60th Birthday of A M Naveira

Valencia July 8-14, 2001

Editors

Olga Gil-Medrano

Vicente Miquel 


\title{
Published by
}

World Scientific Publishing Co. Pte. Ltd.

P O Box 128, Farrer Road, Singapore 912805

USA office: Suite 1B, 1060 Main Street, River Edge, NJ 07661

UK office: 57 Shelton Street, Covent Garden, London WC2H 9HE

\author{
British Library Cataloguing-in-Publication Data \\ A catalogue record for this book is available from the British Library.
}

\section{DIFFERENTIAL GEOMETRY, VALENCIA 2001}

Proceedings of the International Conference Held to Honour the 60th Birthday of A M Naveira Copyright $\odot 2002$ by World Scientific Publishing Co. Pte. Ltd.

All rights reserved. This book, or parts thereof, may not be reproduced in any form or by any means, electronic or mechanical, including photocopying, recording or any information storage and retrieval system now known or to be invented, without written permission from the Publisher.

For photocopying of material in this volume, please pay a copying fee through the Copyright Clearance Center, Inc., 222 Rosewood Drive, Danvers, MA 01923, USA. In this case permission to photocopy is not required from the publisher.

ISBN 981-02-4906-3

Printed in Singapore by Mainland Press 


\section{Preface}

The Congress Differential Geometry Valencia 2001 took place in Valencia from 8 to 14 July 2001. It was organized on occasion of the $60^{\text {th }}$ birthday of Antonio Martnez Naveira, as an homage of his friends and disciples. Some of them constituted the Organizing Committee:

Manuel Barros (Univ. de Granada), Francisco Carreras (Univ. de Valencia), Ximo Gual(Univ. Jaume I), María Luisa Fernández (Univ. País Vasco), Angel Ferrández (Univ. de Murcia), Olga Gil-Medrano (Univ. de Valencia), Luis Hervella (Univ. de Santiago de Compostela), Vicente Miquel (Univ. Valencia) and Salvador Segura (Univ. de Alicante).

There were one hundred and nineteen participants at the conference. The program featured 15 invited lectures (six of fifty minutes and nine of forty minutes), 27 twenty minutes talks and 17 posters. The present volume contains a part of the lectures, talks and posters presented at the Conference and some other contributions of friends of A. M Naveira that, for different reasons, could not attend the conference.

The contributions collected in this volume are mainly on the areas of Riemannian (and pseudo-Riemannian) geometry (curvature properties, variational problems and curvature deformation,..), submanifolds of Riemannian and Lorentzian ambient spaces (with a very special attention to minimal and constant mean curvature submanifolds), structures on manifolds (twistor spaces, $G$-structures, natural bundles,...).

The first paper, by A. Ferrández and L. Hervella, which serves as introduction to the book, remarks the influence of A. M. Naveira in the Differential Geometry in Spain, together with some aspect of his scientific and human personality.

It is a pleasure for us to thank the other members of the Organizing Committee, and all the participants who contributed to the success of the Congress. We are specially indebted to the geometers who accepted to give an invited lecture: L. Alías, T. Aubin, J. P. Bourguignon, M. P. do Carmo, K. Grove, D. Blair, A. Borisenko, F. Brito, P. B. Gilkey, D. L. Johnson, and L. Vanhecke. We extend our warm thanks to S. Montiel, A. Ros and S. Salamon for contributing to these Proceedings.

This Congress was organized under the auspicious of the Department of Geometry and Topology of the University of Valencia, and we give special thanks to the people there who helped in different ways for the preparation and performance of the Congress: F. Mascaró, R. Sivera, P. M. Chacón, A. Hurtado, A. Villanueva and S. Jordá.

The Conference would not have been possible without the support of the 
institutions listed below; to all of them we must express our acknowledgement. Finally, we are specially indebted to the referees for their careful work and to World Scientific for giving us the opportunity to publish these Proceedings.

March, 2002

The Editors

List of Sponsors

Ministerio de Ciencia y Tecnología

Generalitat Valenciana

Universitat de Valencia

Facultat de Matemàtiques

R.S.M.E.

C.A.M. 


\section{List of Participants}

\begin{tabular}{|c|c|c|}
\hline Aledo, Juan Angel & U. Castilla-La Mancha & Spain \\
\hline Alías, Luis José & U. Murcia & Spain \\
\hline Aubin, Thierry & U. Paris VI & France \\
\hline Badura, Marek & U. Lodz & Poland \\
\hline Barros, Manuel & U. Granada & Spain \\
\hline Bartoll-Arnau, Salud & U. P. Valencia & Spain \\
\hline Beltrán, José Vicente & U. Valencia & Spain \\
\hline Bergqvist, Göran & Mälardalen U. & Sweden \\
\hline Binh, Tran Quoc & U. Debrecen & Hungary \\
\hline Biviá, Carles & U. Valencia & Spain \\
\hline Blachowska, Dorota & U. Lodz & Poland \\
\hline Blair, David & Michigan S. U. & U.S.A. \\
\hline Blazic, Novica & U. Belgrade & Yugoslavy \\
\hline Boeckx, Eric & K. U. Leuven & Belgium \\
\hline Bonome, Agustín & U. Santiago de Compostela & Spain \\
\hline Borisenko, Alexander & U. Kharkov & Ukraine \\
\hline Bourguignon, Jean Pierre & I.H.E.S. & France \\
\hline Brasil Junior, Aldir & U. F. Ceará & Brazil \\
\hline Brito, Fabiano & U. Sao Paulo & Brazil \\
\hline Cabrerizo, José Luis & U. Sevilla & Spain \\
\hline Calvaruso, Giovanni & U. Lecce & Italy \\
\hline Carreras, Francisco $\mathbf{J}$. & U. Valencia & Spain \\
\hline Carriazo, Alfonso & U. Sevilla & Spain \\
\hline Chacón, Pablo M. & U. Valencia & Spain \\
\hline Chaves, Rosa Maria & U. São Paulo & Brazil \\
\hline Czarnecki, Maciej & U. Lodzki & Poland \\
\hline de Andrés, Luis Carlos & U. País Vasco & Spain \\
\hline do Carmo, Manfredo & I.M.P.A. & Brazil \\
\hline Domingo-Juan, M. Carmen & U. Valencia & Spain \\
\hline Druetta, María Josefina & U. N. Córdoba & Argentina \\
\hline Etayo, Javier & R.A.C.E.F.N. & Spain \\
\hline Fernández-Andrés, Manuel & U. Sevilla & Spain \\
\hline
\end{tabular}


Fernández-López, Manuel Fernández, Marisa

Ferrández, Angel

Ferrer, Leonor

Fornari, Susana

Gálvez, José Antonio

García-Rio, Eduardo

García, Alicia Nelida

Gil-Medrano, Olga

Gilkey, Peter B

Giménez, Fernando

Giménez-Pastor, Ángel

Girbau, Joan

González-Dávila, Carmelo

González, María del Mar

Grove, Karsten

Gual, Ximo

Herbert, Jorge

Hernández, Luis

Hervella,Luis

Hullet, Eduardo G.

Hurtado, Ana

Javaloyes, Miguel A.

Jelonek, Wlodzimierz

Johnson, David L.

Kamissoko, Dantouma

Koh, Sung-Eun

Koiso, Miyuki

Koufogiorgos, Themis

Lluch, Ana

Lozano, María Teresa

Lucas, Pascual

Lusala, Tsasa

Marchiafava, Stefano

Marinosci, Rosa Anna

Martín del Rey, Ángel

Martínez Antonio

Mascaró, Francisca

Mencía, José. J.

Mercuri, Francesco
U. Santiago de Compostela

U. País Vasco

$\mathrm{U}$, Murcia

U. Granada

U. Minas Gerais

U. Granada

U. Santiago de Compostela

U. N. Cordoba

U. Valencia

U. Oregon

U. P. Valencia

U. Murcia

U. A. Barcelona

U. La Laguna

Priceton U.

U. Maryland

U. Jaume I

U. F. Ceará

CIMAT

U. Santiago de Compostela

U. N. Córdoba

U. Valencia

U. Murcia

Cracow U. T.

Lehigh U.

U. Bretagne O.

U. Konkuk

Kyoto U. E.

U. Ioannina

U. Jaume I

U. Zaragoza

U. Murcia

T. U. Berlin

U. Roma

U. Lecce

U. Salamanca

U. Granada

U. Valencia

U. País Vasco

U. Campinas
Spain

Spain

Spain

Spain

Brazil

Spain

Spain

Argentina

Spain

USA

Spain

Spain

Spain

Spain

USA

USA

Spain

Brazil

México

Spain

Argentina

Spain

Spain

Poland

USA

France

Korea

Japan

Greece

Spain

Spain

Spain

Germany

Italy

Italy

Spain

Spain

Spain

Spain

Brazil 
Mikes, Josef

Min-Oo, Maung

Miquel, Vicente

Mira, Pablo

Montaldo, Stefano

Monterde, Juan

Montesinos Amilibia, Ángel

Moraes, Simone

Morales, Santiago

Naveira, Antonio, M.

Nikitin, Igor

Nuño-Ballesteros, Juanjo

Oh, Seungtaik

Orengo, Javier

Oubiña, José Antonio

Palmer, Vicente

Pereira, Ana

Piu, Paola

Pokorna, Olga

Rakic, Zoran

Reventós, Agustí

Romero-Fuster, M. Carmen

Rybicki, Tomasz

Rylov, Alexander A.

Salvador, Beatriz

Salvai, Marcos

Sambusetti, Andrea

Sanabria, Esther

Sánchez, Miguel

Santisteban, José Antonio

Savo, Alessandro

Scherfner, Mike

Segura, Salvador

Simon, Miles

Simon, Udo

Sivera, Rafael

Suh, Dong Youp

Swift, Tim

Tarrío, Ana

Tomas, Jiri
Palacky U.

McMaster U.

U. Valencia

U. P. Cartagena

U. Cagliari

U. Valencia

U. Valencia

U. F. Viçosa

U. Granada

U. Valencia

G.N.R.C. for I.T.

U. Valencia

K.A.I.S.T.

U. Castilla-LaMancha

U. Santiago de Compostela

U. Jaume I

U. do Minho

U. Cagliari

Czech U. Agriculture

U. Belgrade

U. A. Barcelona

U. Valencia

AGH

Finance Academy

U. C. Madrid

U. N. Córdoba

U. Roma

U. P. Valencia

U. Granada

U. País Vasco

U. Roma

T. U. Berlin

U. Alicante

U. Freiburg

T. U. Berlin

U. Valencia

K.A.I.S.T.

U. West of England

U. A Coruña

T. U. Brno
Czech Republic

Canada

Spain

Spain

Italy

Spain

Spain

Brazil

Spain

Spain

German

Spain

South Korea

Spain

Spain

Spain

Portugal

Italy

Cezch Republic

Yugoslavy

Spain

Spain

Poland

Russia

Spain

Argentina

Italy

Spain

Spain

Spain

Italy

Germany

Spain

Germany

Germany

Spain

South Korea

England

Spain

Czech Republic 


$\begin{array}{lll}\text { Valerio, Bárbara } & \text { U. Sao Paulo } & \text { Brazil } \\ \text { Vanhecke, Lieven } & \text { K. U. Leuven } & \text { Belgium } \\ \text { Walczak, Pawel } & \text { U. Lodzki } & \text { Poland } \\ \text { Wegner, Bernd } & \text { Zentralblatt MATH } & \text { Germany } \\ \text { Wiehe, Martin } & \text { T. U. Berlin } & \text { Germany } \\ \text { Woo, Jeongsoo } & \text { K.A.I.S.T. } & \text { South Korea } \\ \text { Yim, Jin-whan } & \text { K.A.I.S.T. } & \text { South Korea }\end{array}$




\section{Contents}

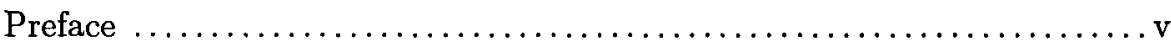

List of Participants ................................... vii

A Tour on the Life and Work of A. M. Naveira ..................... 1

Luis M. Hervella and Angel Ferrández

Some Rigidity Results for Compact Spacelike Surfaces in the

3-dimensional de Sitter Space ............................... 19

Juan A. Aledo and José A. Gálvez

Hypersurfaces with Constant Higher Order Mean Curvature in

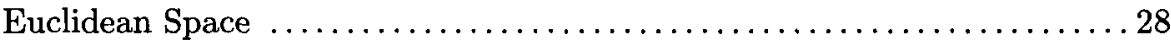

Luis J. Alías and J. Miguel Malacarne

Uniqueness of Spacelike Hypersurfaces with Constant Mean Curvature in Generalized Robertson-Walker Spacetimes . ................... 59 Luis J. Alias and Sebastián Montiel

Best Inequalities of Sobolev Type on Complete Riemannian Manifolds ...70 Thierry Aubin

Critical Points of Willmore-Chen Tension Functionals Manuel Barros

Some Generalizations of Twistor Spaces $\ldots \ldots \ldots \ldots \ldots \ldots \ldots \ldots \ldots \ldots$. 84 David E. Blair

Biharmonic Immersions into Spheres $\ldots \ldots \ldots \ldots \ldots \ldots \ldots \ldots \ldots \ldots \ldots . \ldots \ldots$ R. Caddeo, S. Montaldo and C. Oniciuc

The Gauss Map Spacelike Rotational Surfaces with Constant Mean Curvature in the Lorentz-Minkowski Space ..................... 106 Rosa M.B. Chaves and Cláudia Cueva Cândido

The Intrinsic Torsion of SU(3) and $\mathrm{G}_{2}$ Structures Simon Chiossi and Simon Salamon

$H$-Hypersurfaces with Finite Total Curvature Manfredo P. do Carmo

Null Helices and Degenerate Curves in Lorentzian Spaces

Angel Ferrández, Angel Giménez and Pascual Lucas

Minimal Discs Bounded by Straight Lines

Leonor Ferrer and Francisco Martin 
Volume and Energy of Vector Fields on Spheres. A Survey .......... 167 Olga Gil-Medrano

Spacelike Jordan Osserman Algebraic Curvature Tensors in the

Higher Signature Setting

Peter B. Gilkey and Raina Ivanova

Stability of Surfaces with Constant Mean Curvature in

Three-Dimensional Space Forms Miyuki Koiso

Pseudo-parallel Surfaces in Space Forms Guillermo Antonnio Lobos

Rotational Tchebychev Surfaces of $S^{3}(1)$ Tsasa Lusala

On Holomophically Projective Mappings onto Riemannian

Almost-product Spaces Josef Mikeš and Olga Pokorná

A Characteristic Property of the Catenoid Pablo Mira

Convexity and Semiumbilicity for Surfaces in $\mathbb{R}^{5}$

Simone M. Moraes and María del Carmen Romero-Fuster

The Gauss Map of Minimal Surfaces Antonio Ros

The Fermi-Walker Connection on a Riemannian Conformal Manifold ...253 Beatriz Salvador Allué

On the Volume and Energy of Sections of a Circle Bundle over a Compact Lie Group Marcos Salvai

On Minimal Growth in Group Theory and Riemannian Geometry .....268 Andrea Sambusetti

Deformation of Lipschitz Riemannian Metrics in the Direction of

Their Ricci Curvature

Miles Simon

Some Classification Problems on Natural Bundles Related to

Weil Bundles

Jiři Tomás 